\title{
Supplementary material : A new dataset of soil Carbon and Nitrogen stocks and profiles from an instrumented Greenlandic fen designed to evaluate land-surface models
}

Xavier Morel ${ }^{1}$, Birger Hansen ${ }^{2}$, Christine Delire ${ }^{1}$, Per Ambus ${ }^{2}$, Mikhail Mastepanov $^{3,4}$, and Bertrand Decharme ${ }^{1}$

${ }^{1}$ CNRM UMR 3589, Meteo-France/CNRS, Toulouse, France

${ }^{2}$ Center for Permafrost (CENPERM), Department of Geosciences and Natural Resource Management, University of Copenhagen, Denmark

${ }^{3}$ Departement of Biosciences, Arctic Research Centre, Aarhus University, Roskilde, Denmark

${ }^{4}$ Oulanka research station, University of Oulu, Finland

Correspondence: Xavier Morel (morelxavier1@gmail.com)
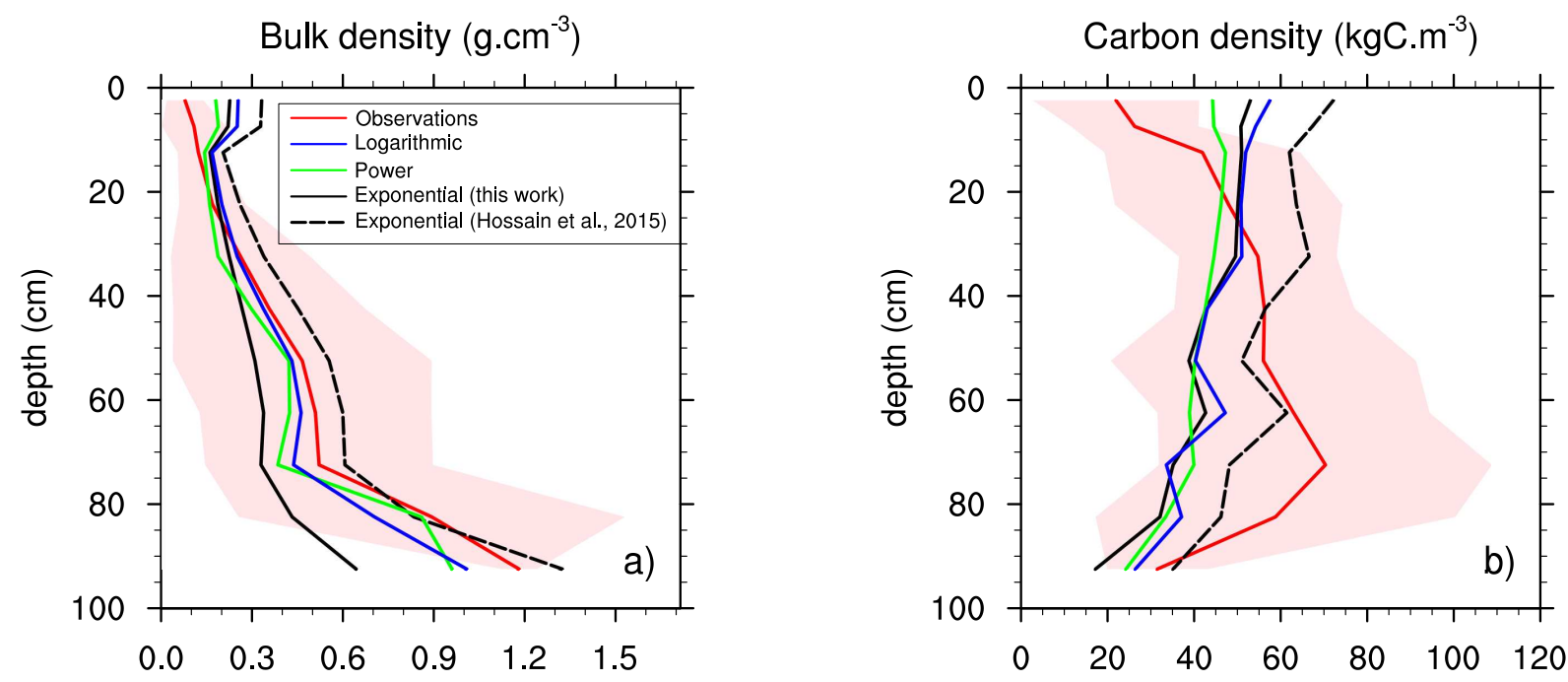

Figure 1. Mean profiles of (a) Bulk density and (b) Carbon density. Red lines represent mean observed values, shaded area the 95\% confidence interval. Dashed black lines represents profiles inferred from the exponential relationship of Hossain et al. (2015). Plan black, green and blue lines represents profiles inferred from the exponential, power and logarithmic relationships presented in Table 5. 


\section{References}

Hossain, M., Chen, W., and Zhang, Y.: Bulk density of mineral and organic soils in the Canada's arctic and sub-arctic, Information Processing in Agriculture, 2, 183 - 190, https://doi.org/https://doi.org/10.1016/j.inpa.2015.09.001, 2015. 